\title{
Choice and assessment of improvement measures critical for process operation (in reference to the requirements of ISO 9001:2015)
}

\author{
Adam Górny, ${ }^{1, *}$ \\ ${ }^{1}$ Poznań University of Technology, Faculty of Management Engineering, 11 Strzelecka St., 60-965 \\ Poznań, Poland
}

\begin{abstract}
Improvement measures should be seen as a sine qua non condition for improving operating efficiency. The measures may vary in nature and range from minor process enhancements to continuous improvements. Improvement measures were selected and evaluated by the FMEA process methodology which helped identify irregularities and their causes as well as indicate which irregularities are most likely to hamper proper process performance. In defining the relationships, reference was made to the requirements of the ISO 9001:2015 standard [1]. Process performance disruptions were assumed to reduce the efficiency and effectiveness of task performance and, most importantly, put process participants at risk of property damage and health impairment. Particular emphasis was placed on occupational safety with a view to reducing the damage caused by failures to secure adequate working conditions. It is only after the scope of analysis has been extended to include criteria related to occupational safety and the ability to ensure worker-friendly working environments that an organization gains the ability to rectify the related errors and, ultimately, attain compliance with ISO9001:2015.
\end{abstract}

\section{Introduction}

Whenever irregularities occur in any field of business, improvement measures become imperative. Improvement may be seen as the achievement of a greater capacity to satisfy requirements. Improvement measures need to be aligned with the specific nature of the tasks at hand with proper account taken of any inconsistencies and the viability of the improvements that are undertaken $[2,3]$.

The goal in assessing improvement measures by identifying the potential benefits is to provide a rationale for their application. A crucial factor is the practical viability of the improvement measures and, ultimately, the ability to attain improvements in every area that is of importance for ensuring the efficient operation of an organization. This presumption may be applied to working conditions, which are at the heart of this paper and which underpin

\footnotetext{
*Corresponding author: adam.gorny@put.poznan.pl
} 
the operation of processes $[4,5]$. The working environment may be seen as a critical area for innovation and improvements that contribute to creating better conditions for process performance [6].

Process efficiency hinges on the effort exerted to improve process functionalities. To achieve it, one needs to carefully select measures based on their evaluation in view of critical aspects of deployments that are essential for the efficient overall operation of an organization [7].

Once working environment issues have been incorporated into the scope of improvement measures, it becomes necessary to recognize human factor requirements. The human factor can be characterized indirectly in terms of an organization's ability to provide its employees with optimal conditions for operating in the working environment. Ultimately, therefore, ensuring adequate conditions for the operation of humans in the working environment will become a systemic requirement that critically affects process efficiency. FMEA enables one to identify irregularities and propose a loss reduction strategy [8].

The application of process FMEA helps identify the root causes behind the emergence of barriers that prevent the satisfaction of requirements associated with specific processes (such as manufacturing). Such factors may be linked to pivotal issues affecting the performance of processes such as the operation of production facilities, machinery and equipment $[9,10]$ as well as the conditions for implementing production processes. Process FMEA may also be employed to shape working environments [11,12] and consequently, in connection with ergonomic requirements, ensure worker comfort [6]. Such comfort, in turn, is bound to boost the ability to carry out processes. Such considerations should be recognized as one the areas for improvement listed in the 2015 edition of the ISO 9000 series of standards.

\section{Improvement measures}

\subsection{Nature of improvement measures}

Improvement measures may be defined as enhancements of the tasks carried out by an organization. Such measures range from the minor tweaking of processes to continuous improvements constituting part and parcel of the systemic approach to management [3]. The ISO 9000 standard [13] defines improvement measures as actions taken to make an organization more efficient. Such measures may help reduce the number of failures and complaints, boost production efficiency, cut operating expenses, etc. Once a non-conformity occurs, corrective action is required to remedy the problem and minimize its consequences. To this aim, an evaluation is in order of the need to remedy the non-conformities and, most of all, prevent their recurrence in the same or another location. The next step is to implement such remedies and appraise their effectiveness. Any improvement measures should adequately address the effects of any non-conformities that have been discovered $[1,14]$.

The measures taken should focus on ensuring the lasting success of an organization, defined as the achievement and retention over the long haul of the ability to accomplish the adopted objectives $[11,15]$. Such measures should extend to all factors and conditions that influence the attainment of an adopted goal. Therefore, decisions must be based on factual evidence, which in turn makes it necessary to conduct a thorough study of the irregularity in question [16].

To ensure that improvement measures are effectively carried out and that the anticipated benefits result from an organization's adopted operating strategy, it is often advisable to employ the tools and improvement methods that help select the proper improvement measures and properly evaluate improvement results $[12,14,16,17]$. 


\subsection{Measures improving process operation}

Improvement measures are a sine qua non condition for improving an organization's processes [18]. Improvement measures are only effective if they are consistent with the nature of any non-conformities. If chosen properly, such measures help carry out improvement tasks according to plan and in a duplicable manner based on scientific presumptions as well as gather such data and information as is necessary to select adequate improvement methods. To solve the problem effectively, one needs knowledge of the concerned process, access to proper identification and improvement tools and the ability to apply them. As improvement outcomes should be measurable, it is critical to define indicators that will enable an organization to e.g. identify the possible benefits, specify the verification timeline and assign responsibilities for specific measures [3]. Such methods include process FMEA which can be used to influence the quality of performing specified tasks $[16,19]$. The fundamental aim in applying process FMEA is to raise error detection rates at early stages of process design and consequently generate savings on the cost of future improvement measures [14].

While conducting an analysis, one should bear in mind that its successful completion depends on the nature of the existing non-conformities. Therefore, improvement measures must be consistent with the nature of such non-conformities. The choice of improvement measures can only be correct if the issues at hand are properly analyzed so as to adequately define their characteristics. The tools employed must help find all significant issues that affect non-conformities and assess their impact [2].

The FMEA analysis employed to define the nature of a problem may be carried out [16, 17]:

- Systemically, in which case processes will be addressed in their entirety as a system made up of subsystems which in turn comprise their own lower level subsystems,

- In a problem-centered approach, in which the analysis extends to all areas in which irregularities are found.

This helps identify the problem in areas of significance for improvement measures. The improvements entail rectifying discrepancies between the existing and the desired states. They may also be seen as a way to increase process effectiveness and efficiency. One result of improvement measures is the elimination of irregularities which stand in the way of process operation.

Process performance verification can be described as the assurance of [16, 17]:

- Proper process planning that helps answer the question of what is the appropriate course of process operation that guarantees the fulfillment of requirements,

- Proper process performance, especially where such performance and the achievement of the desired improvement outcomes are at risk,

- Achieving improvement outcomes regardless of the non-conformities faced.

The FMEA technique is a teamwork-based method which can be used to detect, prevent, eliminate and control potential process errors [18]. Its application helps consistently and lastingly eliminate process weaknesses. This is achieved by recognizing the real causes of irregularities and employing adequate preventive measures of proven effectiveness.

An additional option of using process FMEA relies on the principle of "continuous improvement" and specifically on successive analyses of the process which help identify irregularities (failures) and make adjustments and adopt solutions that effectively eliminate the causes of defects. Such analyses may also give rise to new ideas for measures that improve the operation of processes. 


\section{Choice and application of improvement measures}

\subsection{Process FMEA methodology as a method of identifying and selecting improvement measures}

The evaluation and choice of solutions suited for the process FMEA methodology requires a three-staged sequence of actions [3, 14, 16, 17]:

- Stage 1 covers a preparation which involves defining the process relationships that arise in the course of performing a specified task. This typically entails a prior breakdown of the task into processes or elementary operations on an as-needed basis. To ensure that the measures taken are effective, it is critical to employ teamwork and adopt as many presumptions as possible that will enable the organization to properly analyze the process at hand.

Despite the breakdown, processes should be viewed as a complex amalgam of subsystems, each of which comprises its own lower-level subsystems. One should recognize that each part of the system plays its specific role. A proper breakdown reflecting to the complexity of the system makes it possible to commence the analysis at any level, which is particularly important when dealing with complex processes.

- Stage 2 represents the process FMEA analysis proper. At this stage, the organization needs to identify any potential process failures. A failure is defined as any improper operation of a process, i.e. such process performance as does not lead to the desired outcome. Failures of this kind are described with reference to their type, impact and cause. A failure cause is an improper operation of a lower level subsystem. Its impacts affect a subsystem of a higher level.

Once an organization has identified the sequence of events that trigger the occurrence of a failure, it is in a position to assess the likelihood of the failure in specific processes, specify the rate of failure detection prior to process completion and prior to the occurrence of the adverse effects that influence the next sub-process and assess the significance of the failure for the proper operation of processes and for process performance outcomes. This kind of numeric evaluation comes on a scale from 1 to 10 depending on the severity of the impact of a given criterion.

Descriptions of evaluation criteria and examples of tendencies in the evaluation factors which influence the numerical scores are summarized in Figure 1.

Once calculated, the numbers describing a failure's impact on the end result of a process can be used to arrive at the failure risk priority number $(\mathrm{RPN}=\mathrm{O} \times \mathrm{D} \times \mathrm{C})$, which ranks on a scale from 1 to 1000 . The selection of critical process failures is possible by reference to the number representing the priority of the failure risk. High failure risk priorities point to the need to take preventive action aimed at modifying process performance.

- Stage 3 concerns the adoption of and supervision over preventive measures. Stage 3 focuses on completing the tasks identified at Stage 2. The findings of analyses are used as a basis for modifying processes with a view to eliminating failure causes or mitigating their impacts.

In order to carry out improvement measures, it is critical to define the necessary means, identify persons responsible for taking action and define the related timeline. Commonly, costing figures are additionally provided with an eye to establishing the benefit to cost ratio $[14,20]$.

The indicator (priority number) identified at Stage 2 is used to define the sequence of improvement measures in the order of criticality. The higher the indicator, the more severe the concerned failure. Where differences between criticality levels are minor, more subtle criteria should be used to rank failure causes. In such cases, it is recommended that 
component evaluations be used as ranking weights starting with failure severity, followed by failure occurrence frequency and failure detectability [17,21].

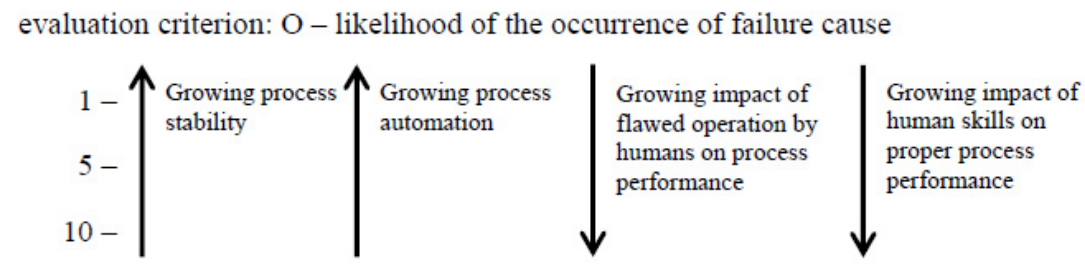

evaluation criterion: $\mathrm{D}$ - failure cause detectability before occurrence

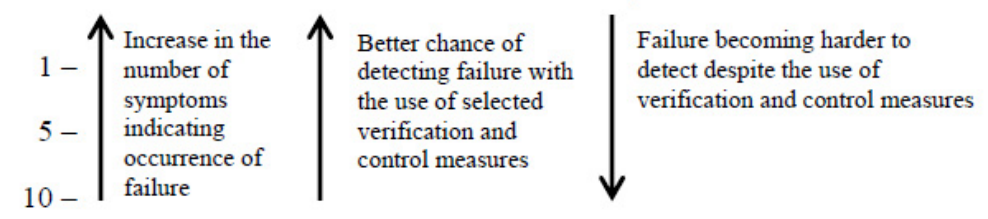

evaluation criterion: $\mathrm{C}$ - failure criticality for production process outcomes

\begin{tabular}{|c|c|c|c|c|}
\hline $1-$ & $\begin{array}{l}\text { Greater } \\
\text { significance of } \\
\text { failure for } \\
\text { process safety } \\
\text { evaluation }\end{array}$ & $\begin{array}{l}\text { Greater significance } \\
\text { of the adverse } \\
\text { impact of factors } \\
\text { that are critical for } \\
\text { process performance }\end{array}$ & $\begin{array}{l}\text { Greater } \\
\text { dissatisfaction of } \\
\text { process } \\
\text { participant with } \\
\text { process } \\
\text { performance }\end{array}$ & $\begin{array}{l}\text { Greater significance } \\
\text { of failure for the } \\
\text { evaluation of the } \\
\text { production of } \\
\text { product or the } \\
\text { rendition of service }\end{array}$ \\
\hline
\end{tabular}

Fig. 1. Description of evaluations employed in the process FMEA method.

Source: Own research based on $[14,17,21]$.

\subsection{Applicable of process FMEA to select improvement measures (example)}

The methodology described in Section 3.1 was applied to assess the criticality of failures and the choice of improvement measures in a company that carries out welding work. The procedure helped link process disruptions with such effects as reduced labor efficiency, lower performance accuracy, material waste and employee health impairment.

The analysis focused on the process of tank cover welding. Such welding was conducted in a manufacturer of pressure containers that comply with harmonized European legislation, including Directive 2014/68/EU [22]. The company has been awarded permits to manufacture pressure containers from Polish supervisory authorities, including the Office of Technical Inspection (UDT).

A critical precondition for producing weld joints of satisfactory quality is to put in place a proper technological regime covering the entire welding process. Due to the nature of the work, there is also a risk of workers being poisoned by the gases and fumes from electrode melting, which will result in a substandard joint.

The evaluation was conducted by a team appointed by the company's management. Its members were in-house technological engineers, constructors and occupational health and safety experts. Also employed in an auxiliary capacity was an external expert tasked with the methodological supervision over the evaluation process. The irregularities involved and the severity of their impact are shown in Table 1. 
Table 1. Irregularities assessed and evaluation scores

\begin{tabular}{|c|c|c|c|c|c|c|c|c|c|c|}
\hline \multicolumn{11}{|c|}{ Item assessed: the process of tank cover welding } \\
\hline \multicolumn{7}{|c|}{ Evaluation aspect: } & \multicolumn{4}{|c|}{ Evaluation criterion: } \\
\hline \multicolumn{2}{|c|}{ Function } & Effect & Failure & Cause & Prevention & Detection & $\mathrm{O}$ & $\mathrm{D}$ & $\mathrm{C}$ & RPN \\
\hline a) & & 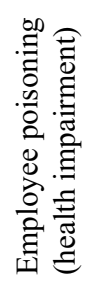 & 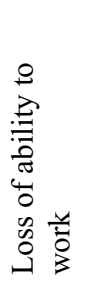 & 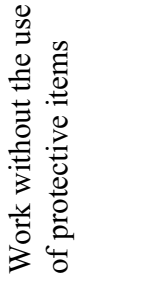 & 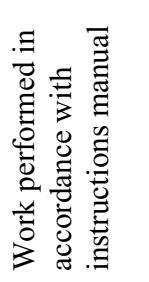 & 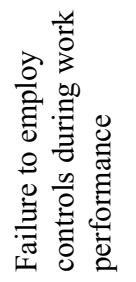 & 8 & 8 & 9 & 576 \\
\hline b) & 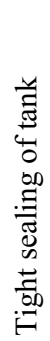 & 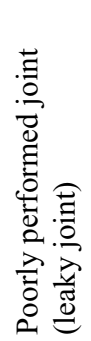 & 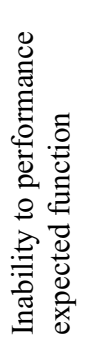 & 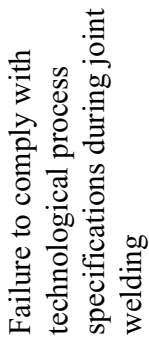 & 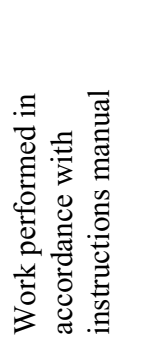 & 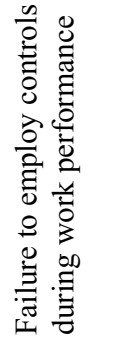 & 8 & 9 & 7 & 504 \\
\hline
\end{tabular}

Table 2. Process evaluation indicators after the application of improvement measures.

\begin{tabular}{|l|l|l|c|c|c|c|}
\cline { 2 - 6 } \multicolumn{1}{c|}{} & \multicolumn{2}{|l|}{$\begin{array}{l}\text { Employed improvement measures increasing the ability to perform } \\
\text { the process of welding tank cover }\end{array}$} & \multicolumn{3}{|c|}{ Evaluation criterion: } \\
\cline { 2 - 7 } \multicolumn{1}{c|}{} & $\begin{array}{l}\text { Preventing the occurrence of } \\
\text { defect causes }\end{array}$ & Detectability of defect causes & O & D & C & RPN \\
\hline a) & $\begin{array}{l}\text { Ensuring effective ventilation at } \\
\text { workstation and making the use } \\
\text { of PPE mandatory }\end{array}$ & $\begin{array}{l}\text { Adoption of control and } \\
\text { monitoring principles and their } \\
\text { application }\end{array}$ & 4 & 5 & 9 & 180 \\
\hline b) & $\begin{array}{l}\text { Ensuring proper parameters and } \\
\text { compliance with technological } \\
\text { joint welding regimes }\end{array}$ & $\begin{array}{l}\text { Adoption of control and } \\
\text { monitoring principles and their } \\
\text { application }\end{array}$ & 3 & 7 & 8 & 168 \\
\hline
\end{tabular}

\section{Possibilities of and potential benefits from applying the process FMEA method}

Due to the universal nature of the process FMEA method, it is applicable in practically any industry in which a high degree of reliability is required. The use of the method is recommended particularly at the stage of designing difficult-to-control processes and during their performance for the purposes of improvement. A significant benefit of the process FMEA method is that it can be employed in the manufacturing operations of any kind, wherever inefficient processes may result in substantial losses [20]. This benefit can be attributed to the method's nature. The evaluation that forms a part of the method can only be appropriate if extensive information has been gathered about the facility in question $[14,16$, 19, 21].

The research has found the need to examine links between the factors that are critical for process operation and any improvement measures. This is necessary for the FMEA to produce the expected benefits. 
The ability to rectify a problem classified for priority (with an RPN) depends heavily on:

- The likelihood of the occurrence of the causes of a specific defect,

- The detectability of the causes of such a defect,

- The ability to apply measures that eliminate defect causes and are well suited for the company's operating methods,

- Access to resources required to deploy measures that eliminate defect causes,

- Defect significance for the relevant process.

Irregularity analysis should begin with indicating the nature of any irregularities. These are commonly described as the inability to perform a vital function. This step is followed by a causal analysis aimed at identifying the root cause of the issue [2, 23].

The steps taken in analyzing a problem and the measures adopted to rectify it are shown in Figure 2.

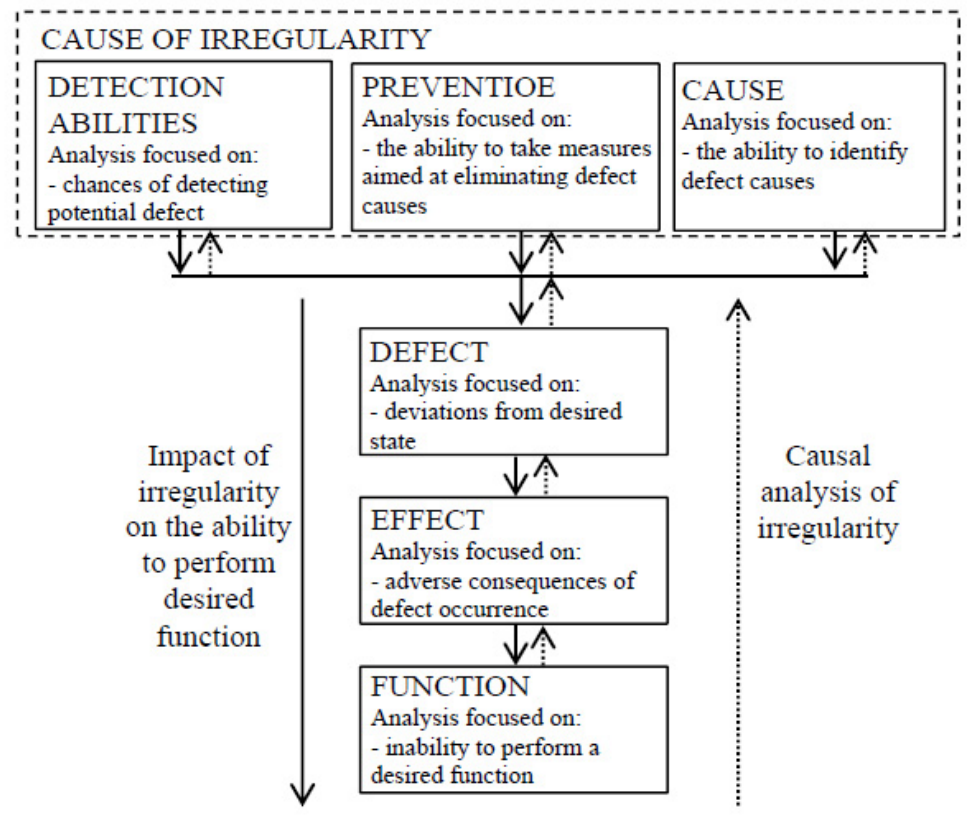

Fig. 2. Steps taken to identify and rectify irregularities.

The potential benefits depend on the approach taken [14]. In the problem-centered approach, analysis is extended to all areas in which irregularities were discovered. The drawback of this approach is its limited capacity for correcting potential risks throughout process performance. The analysis is limited to the risks which have already surfaced and attracted attention. An inexperienced evaluation team may easily overlook the risks that are rare but nevertheless generate severe consequences. The advantage of the problem-centered approach is the simplicity and conciseness of the analysis it involves [17].

The systemic approach makes the analysis general as well as more transparent. The approach is better at identifying such potential risks in the process as have not yet surfaced or that are relatively rare [17]. The systemic approach requires a well-trained evaluation team and strict compliance with the adopted procedures.

Regardless of which approach is taken, the FMEA method does not generate new solutions. All it does is point to the parts of the process that are critical and suggest why it seriously hinders efficient performance $[3,11,19]$. This requires engineering (and also technological) knowledge, the awareness of standards and legal regulations and experience 
working with the processes at hand. It may be viewed as a key resource to be used in carrying out improvement measures.

Some of the most significant areas of management in today's enterprise are quality, environment and occupational health and safety. By incorporating the above occupational health and safety requirements and issues into the management system, an organization will gain the ability to view the problem as an interdisciplinary area of improvement. An essential part of the improvement is to modify not only process performance but also the environment in which the process takes place. This follows from ISO 9001 which emphasizes the importance of focusing not only on process implementation but also on ensuring that the conditions for process performance are adequate. A study of the case discussed in section 3.2 shows that failures to ensure an adequate working environment, use personal protection equipment and ensure correct process specifications (proper technological specifications for welding) will all lead to the same consequences, i.e. the production of leaky tanks. By adopting proper prevention and control measures that guarantee the detection of defects, the manufacturer will accomplish the same result, which can be described as improved process effectiveness. This has been demonstrated by the process assessment results shown in Table 2. The resulting benefits can be evaluated by comparing the results of process assessments (RPN) carried out before and after improvement measures (see Table 1). In both case a) and case b), the measures taken have helped reduce the risk of tank dysfunctionality (caused by leaky joints) by a factor of ca. 3 , i.e. down to an acceptable level.

The acceptable and unacceptable ranges of non-conformity as well as suggested measures to be taken to maintain or improve current status have been summarized in Table 3 .

Table 3. Acceptable and unacceptable ranges of non-conformity [24, 25].

\begin{tabular}{|c|l|l|}
\hline RPN value & \multicolumn{1}{|c|}{ Level of irregularity } & \multicolumn{1}{c|}{ Suggested measures } \\
\hline Acceptable irregularity range & No process improvements are necessary \\
\hline$(0-200)$ & Minor (tolerable) & Process improvements are recommended \\
\hline$<200-500)$ & Mild (moderate) & Process improvements are necessary \\
\hline$<500-800)$ & Medium (significant) & \\
\hline Unacceptable irregularity range & $\begin{array}{l}\text { Processes must be suspended until } \\
\text { improvements are made }\end{array}$ \\
\hline$<800-1000>$ & Major &
\end{tabular}

The assessment methodology requires that specific causes of irregularities be identified by independently describing the relevant processes [26, 27]. Simultaneous evaluations carried out at multiple process points will reveal a number of issues associated with process impacts on workers.

The requirements in these fields are often mutually complementary. Therefore, to identify issues, one needs to employ methods and tools that make it possible to gain a global perspective on the issue at hand $[6,12]$. One such tool is process FMEA which helps $[7,12$, 27]:

- Recognize the factors that hinder the satisfaction of requirements or disrupt processes; such factors may be associated with the conditions that affect process operation and that are vital to their improvement,

- By consistently identifying and eliminating failures in e.g. production processes, applying the right preventive measures and avoiding the process failures that have been identified on a preliminary basis but that remain unknown, it is possible to achieve the state of "zero failures" [21],

- Identify problems encountered at various stages of process performance,

- Utilize the process approach structure which enables one to link inputs (such as data and information) with outputs (such as decisions). 
Without a doubt, one of the drawbacks of the method is that it often leads to wrong conclusions unless the evaluation team employed is highly experienced. To relate the issue at hand to working conditions, one needs to account for the relationships between man technical item - working environment in the process in question. An inexperienced evaluation team may find it difficult to define the problems clearly and link them correctly with specific aspects of process performance $[4,20,26]$. To obtain objective conclusions, it is not enough to demonstrate the direct impact of given risks. What needs to be done as well is to look into the risk of the existing irregularities generating further effects (losses) at a later time. As losses of this kind usually follow a definable loss emergence pattern, timely improvement measures will help effectively break the cycle of problem escalation.

\section{Conclusions}

Early on (in the early $20^{\text {th }}$ century), the FMEA method continued to gain popularity in an ever greater number of applications in preparing complex processes in astronautics, nuclear engineering and aviation. By today, the scope of its use has grown substantially. FMEA is a preventive method which helps identify defects and their causes sufficiently in advance. Organizations relying on complex manufacturing processes employ FMEA to identify issues associated with many areas of their operations. This is particularly critical where multiple problems coincide in such varying fields as:

- Ensuring continuous production at a required efficiency level,

- Maintaining technical machinery and equipment in proper working condition,

- Managing the impacts on the environment as well as on occupational health and safety,

- Assuring the required quality of products and services,

- Ensuring the activities are sufficiently profitable.

No matter how complex an organization's processes are, it is always possible to identify issues having the greatest influence on final outputs. The approach helps detect key problems and assess their impacts. In the case discussed in section 3.2, the requirement must be met to describe:

- The effects of the company's inability to produce tanks that meet the desired functionality specifications,

- The way in which the defects render the organization incapable of achieving the required functionality,

- The immediate causes of defects as well as the underlying causes of defect occurrence,

- The possibility of employing improvement measures,

- The conditions in which a defect can be detected, the likelihood of its detection and the measures available to prevent defect occurrence.

In this process, the organization will also detect defects having the most adverse impact on process efficiency and effectiveness. Such impacts include the risk of health impairment and, in the most extreme cases, life-threatening risks.

Process FMEA helps identify potential threats to process performance. The method should be recognized as useful for recording and monitoring/observing measures aimed at averting any potential impacts. If used properly, FMEA will lower process costs while ensuring the required efficiency and quality. Where ISO 9001:2015 applies, process FMEA helps identify issues and make improvements against a range of requirements which translate into process efficiency. As a consequence, the conditions needed for adequate process performance will be created.

In addition, organizations rely on simulations to help define the potential effects of improvement measures. However, significant limitations must be taken into account in applying such techniques. 
To ensure that evaluations are objective, it is critical to obtain information on the nature of irregularities as well as their causes and effects. The identification process needs to be conducted in a way that ensures that all irregularities are detected and properly described. During an FMEA analysis, account must be taken of the long-term consequences of the occurrence of specific types of errors.

The use of the FMEA method in process analysis brings into focus a number of requirements that could be overlooked without such comprehensive analysis. These include requirements associated with the management of the working environment that help ensure working conditions that are friendly to production floor workers. Where a broad approach to an issue is critical for the fulfillment of systemic requirements, process FMEA will significantly facilitate the evaluation and selection of best improvement measures.

\section{References}

1. EN ISO 9001:2015, Quality management systems. Requirements (ISO 9001:2015), European Committee for Standardization, Brussels

2. T.A. Carbone and D.D. Tippett, Engineering Management J., 16(4), 28-35 (2004)

3. C.J. Price, N.S. Taylor, Reliability Engineering \& System Safety, 76(1), 1-10 (2012)

4. A. Górny, The Elements of Work Environment in the Improvement Process of Quality Management System Structure, In: W. Karwowski, G. Salvendy (Eds.), Advances in Human Factors, Ergonomics and Safety in Manufacturing and Service Industries, 599606 (AHFE 2011)

5. A. Kawecka-Endler, B. Mrugalska, Human-Computer Interaction: Applications and Services, III, 8512, 700-709 (2014)

6. A. Górny, Foundation of Control and Management Sciences, 11, 127-138 (2008)

7. A. Sutrisnoa, I. Gunawanb, S. Tangkumanc, Procedia Manufacturing 4, 23-29 (2015)

8. C. Estorilio, R.K. Posso, Int. J. of Quality and Reliability Management, 27(6), 721-733 (2010)

9. A. Górny, Evaluation of compliance with minimum safety requirements in machine operations: A case of assessing the control devices of a press, In: P.M. Arezes, at al. (Eds.), Occupational Safety and Hygiene, 497-501 (Taylor and Francis Group, London 2013)

10. B. Mrugalska, P.M. Arezes, Safety Requirements for Machinery in Practice, In: P.M. Arezes, at al. (Eds.), Occupational Safety and Hygiene, 97-101 (Taylor and Francis Group, London 2013)

11. A. Kawecka-Endler, B. Mrugalska, Analysis of Changes in Work Processes, In: W. Karwowski (Ed.), Advances in Social and Organizational Factors, 672-681 (AHFE 2012)

12. A. Górny, Management Systems in Production Engineering, 3, 106-111 (2014)

13. EN ISO 9000:2015, Quality management systems. Fundamentals and vocabulary (ISO 9000:2015), European Committee for Standardization, Brussels

14. M. Dudek-Burlikowska, J. of Achievements in Materials and Manufacturing Engineering, 45(1), 89-102 (2011)

15. EN ISO 9004:2009, Managing for the sustained success of an organization. A quality management approach (ISO 9004:2009), European Committee for Standardization, Brussels

16. D.H. Stamatis, Failure Mode and Effect Analysis. FMEA from Theory to Execution, $2^{\text {nd }}$ edition, (ASQ Quality Press, Milwaukee 2003)

17. A. Hamrol, Quality management with examples (Wydawnictwo Naukowe PWN, Warszawa 2005) 
18. M. Bahrami, D. H. Bazzaz, S. M. Mojtaba, Procedia - Social and Behavioral Sciences, 41, 418-425 (2012)

19. C. S. Carlso, Effective FMEAs. Achieving Safe, Reliable, and Economical Products and Processes Using Failure Mode and Effects Analysis (John Willey and Sons, New Jersey 2012)

20. S. Kmenta, K. Ishii, J. of Mechanical Design, 12(6), 1027 (2004)

21. B. Gajdzik, A. Wyciślik, Quality, environment and safety in enterprise management (Wydawnictwo Politechniki Śląskiej, Gliwice 2008)

22. Directive 2014/68/EU of the European Parliament and of the Council of 15 May 2014 on the harmonization of the laws of the Member States relating to the making available on the market of pressure equipment, OJ L 189, 27.6.2014, pp. 164-259

23. A. Shahin, Int. J. of Quality and Reliability Management, 21(7), 731-746 (2004)

24. A. Górny, Wykorzystanie FMEA w procesie identyfikacji zagrożeń i oceny ryzyka zawodowego, In: J. Charytonowicz, W. Pilecki (Eds.), Zastosowania Ergonomii/ Wybrane kierunki badań ergonomicznych w 2008 roku, 75-86 (Wyd. Polskiego Towarzystwa Ergonomicznego PTErg, Oddział we Wrocławiu, Wrocław 2008)

25. A. Górny, Wykorzystanie FMEA procesu w analizie zdarzeń wypadkowych i doskonaleniu warunków wykonywania pracy, In: J. Charytonowicz (Ed.), Zastosowania Ergonomii. Wybrane kierunki badań ergonomicznych w 2016 roku, 41-55 (Wyd. Polskiego Towarzystwa Ergonomicznego PTErg, Oddział we Wrocławiu, Wrocław 2016)

26. H.S. Bunney, B.G. Dale, The TQM Magazine, 9(3), 183-189 (1997)

27. S.G. Teng, S.M. Ho, D. Shumar, P.C. Liu, Int. J. of Quality and Reliability Management, 23(2), 179-196 (2006) 